\title{
PERCEPÇÃO DE MÃES PRESIDIÁRIAS SOBRE OS MOTIVOS QUE DIFICULTAM \\ A VIVÊNCIA DO BINÔMIO
}

\author{
PERCEPTION OF MOTHERS PRISONERS ON \\ GROUNDS OF EXPERIENCE DIFFICULT BINOMIAL
}

\author{
PERCEPCIÓN DE LAS MADRES PRESOS DE LOS \\ MOTIVOS QUE DIFICIL EXPERIÊNCIA UN BINOMIO
}

\begin{abstract}
Aparecida do Nascimento Vieira de Araújo*, Luciana Braga de Moura**, Ezequiel Araújo Ferreira Neto***, Tânia Christiane Ferreira Bispo****
\end{abstract}

\begin{abstract}
Percepção de mães presidiárias sobre os motivos que dificultam a vivência do binômio: TCC de conclusão de curso de graduação de Enfermagem do Centro Universitário Jorge Amado. Ser mulher gestante e presidiária: difíceis caminhos, do NUPESV - Núcleo de Pesquisa Saúde e Violência da Universidade do Estado da Bahia - UNEB.

*Enfermeira, graduada pelo Centro Universitário Jorge Amado. Pós Graduanda em Enfermagem do Trabalho pelo Centro Universitário Internacional UNINTER. Salvador, Bahia, Brasil. Integrante do NUPESV, ${ }^{* *}$ Enfermeira, graduada pelo Centro Universitário Jorge Amado. Salvador, Bahia, Brasil. Integrante do NUPESV, ${ }^{* * *}$ Enfermeiro, graduado pelo Centro Universitário Jorge Amado. Salvador, Bahia, Brasil. Integrante do NUPESV, ${ }^{* * * * E n f e r m e i r a, ~ d o u t o r a ~ e ~ P o ́ s-d o u t o r a, ~ e m ~}$ Saúde Coletiva pelo Instituto de Saúde Coletiva da UFBA- ISC/UFBA, Mestre em Enfermagem na Atenção à saúde da Mulher, Especialista em Enfermagem Obstétrica. Professora da UNIJORGE. Salvador, Bahia, Brasil. Coordenadora do projeto de pesquisa: Ser Mulher Gestante e presidiária: difíceis caminhos e do NUPESV.
\end{abstract}

\section{Resumo}

O presente estudo teve como objetivo analisar a percepção de mulheres presidiárias sobre o processo amamentação em um Conjunto Penal Feminino da Bahia, para inferir o objetivo proposto executou-se uma pesquisa de abordagem qualitativa. Foi utilizado como instrumento para a coleta de dados a entrevista semi-estruturada e individual, realizada com sete presidiárias e analisadas de acordo com a análise técnica de Bardin. Os resultados apontaram que o Conjunto Penal Feminino estabelece o direito do bebê à amamentação, mas a insatisfação com a estrutura física e a assistência à saúde foram destacadas pelas presidiárias, evidenciando falhas no sistema carcerário. A partir dos relatos concluímos que sobre a percepção das presidiárias houve concordância geral a respeito do descontentamento com a falta de estrutura, assistência e benefícios para as boas práticas da amamentação.

Palavras-chave: Dificuldades; Prisões; Mulheres. 


\begin{abstract}
The present study aimed to analyze the perception of female prisoners on the nursing process in a Joint Criminal Women's Bahia, for inferring the proposed objective ran up a qualitative study. It was used as a tool for collecting data and semi-structured individual held seven prisoners and analyzed according to the technical analysis of Bardin. The results showed that the set of Criminal Female establishes the right baby for breastfeeding, but dissatisfaction with the physical structure and health care were highlighted by the prisoners, highlighting flaws in the prison system. From the reports we conclude that on the perception of female prisoners there was general agreement about the discontent with the lack of infrastructure, assistance and benefits to breastfeeding practices.
\end{abstract}

Keywords: Difficulties; Prisons; Women.

\title{
Resumen
}

El presente estudio tuvo como objetivo analizar la percepción de las mujeres presas en el proceso de enfermería en un conjunto Bahia mujeres de lo Penal, para inferir el objetivo propuesto subió un estudio cualitativo. Fue utilizado como una herramienta de recogida de datos y semi-estructuradas individuales celebró siete prisioneros y analizados de acuerdo con el análisis técnico de Bardin. Los resultados mostraron que el conjunto Penal Mujer establece el derecho a la lactancia del bebé, pero descontento con la estructura física y la salud fueron destacados por los prisioneros, poniendo de relieve las fallas en el sistema penitenciario. De los informes se concluye que en la percepción de las mujeres presas hubo un acuerdo general sobre el descontento con la falta de infraestructura, la asistencia y las prestaciones a las prácticas de lactancia materna.

Palabras clave: Dificultades; Prisiones; Mujeres.

\section{INTRODUÇÃO}

No Brasil o Sistema Penitenciário passa por privações que vem se acumulando há muitos anos, a começar pela deficiência na construção de novos presídios. Fatores como péssimas condições de higiene, alimentação, lotação e imperícia em fomentar seu papel ressocializador são incapacidades do Sistema Prisional, episódios esses que depreciam a figura do sistema no Brasil. ${ }^{(1)}$

No ano de 2000 a população carcerária Brasileira totalizava 232.755 detentos ao passo que em Junho de 2011 registravam 513.802 reclusos, estes dados mostram que a população carcerária cresceu $121 \%$ conforme ultimo balanço realizado pelo Departamento Penitenciário Nacional (DEPEN). Entrementes, o número de mulheres presidiárias aumentou $252 \%$ nesta ocasião em 2000 totalizavam 10.112 presidiárias com uma representação de $4,3 \%$ da população carcerária Nacional, todavia em 2011 houve um acréscimo para 35.596 mulheres com um percentual de 7,4\%. ${ }^{(2)}$ Segundo dados do Ministério da Justiça essas mulheres em 2012 representarão $7,65 \%$ da população total do país. ${ }^{(3)}$ 
Mesmo que a prisão se apresente em sua grande maioria dominada pelo sexo masculino, a participação da mulher vem aumentando consideravelmente ao longo dos anos, tanto na sociedade quanto na criminalidade, na sua maioria essas presidiárias apresentam consigo a marca da miséria, por possuir uma desigualdade socioeconômica, com isso carrega consigo um estigma, com sua entrada na prisão recebem uma cicatriz de criminosa que levará por toda sua vida mesmo após a liberdade.

Considerando que a grande parte dessas presidiárias encontrava-se grávidas durante o seu envolvimento com o crime, nesse contexto muitos são os quesitos que merecem uma sensatez quando se refere a mulheres privadas de liberdade como a gravidez, maternidade e amamentação. Diante deste cenário, a situação se exacerba principalmente para as presidiárias gestantes/mães, as que sofrem violência duas vezes.

O que nos leva a sobrepensar que independente da natureza de seu crime mantém o direito de gozar dos mais elevados padrões de assistência à saúde em especial na gravidez com o pré-natal, preservando assim os demais direito peculiares a sua cidadania. Em 2009 foi instituída lei $n^{\circ} 11.942$ em seu artigo $14, \int 3^{\circ}$, mencionam que: "Será assegurado acompanhamento médico à mulher, principalmente no pré-natal e no pós-parto, extensivo ao recém-nascido". Nessa mesma lei em seu artigo $83, \int 2^{\circ}$, "Preconiza que os estabelecimentos penais destinados à mulher serão dotados de berçário, onde as condenadas possam cuidar de seus filhos, inclusive amamentá-los no mínimo, até 6 (seis) meses de idade".(4)

A Organização Mundial da Saúde (OMS) e o Ministério da Saúde determinam que a amamentação exclusiva deva acontecer pelo menos, nos seis primeiros meses de vida do bebê, por entender que, o aleitamento materno é imprescindível para a saúde da criança até o $6^{\circ}$ mês por ter importantes fontes de nutrientes, após esse período é necessário introduzir alimentações complementares, pois já não supre mais as necessidades, todavia recomenda-se continuar o aleitamento até os dois anos de idade ou mais. ${ }^{(5,6)}$
Retrair esse direito da interna e, especialmente, da criança, em ser amamentada, representa uma espécie de transmissão da pena, contestando claramente 0 art. $5^{\circ}$, inciso XLV da Constituição Federal 88 , o qual determina que nenhuma pena passe do condenado. ${ }^{(7)}$

Nessa mesma Constituição Federal 88, em seu art. $5^{\circ}$, inciso L, preconiza que "as presidiárias serão asseguradas condições para que possam permanecer com seus filhos durante o período de amamentação". (7) Assim como o Estatuto da Criança e do Adolescente (ECA) em seu art. $9^{\circ}$, diz que: "O poder público, as instituições e os empregadores propiciarão condições adequadas ao aleitamento materno, inclusive aos filhos de mães submetidas à medida privativa de liberdade". Entretanto, observa-se uma enorme distância entre as disposições legais e a realidade. ${ }^{(8)}$

Segundo os dados levantados no Ministério da Justiça, no Brasil entre fevereiro e março de 2008 , $1,24 \%$ das mulheres presas encontravam-se grávidas. Neste mesmo período, existiam 0,91\% de mulheres encarceradas amamentando. Notou-se que $1,04 \%$ das presidiárias possuíam filhos em sua companhia, e que o tempo de permanência com a mãe na prisão variava entre quatro meses e sete anos de idade. (3)

Discorrendo sobre as dificuldades que as muIheres no ciclo gravídico puerperal enfrentam dentro do Sistema prisional, podemos citar o Processo de Amamentação. É sabido que o aleitamento materno traz benefícios não apenas para o bebê, mas também para a mãe, indicadores comprovam várias vantagens. ${ }^{(1)}$

Além de ser um alimento completo para o bebê, por fortalecer o sistema imunológico da criança, desenvolvendo anticorpos, protegendo contra afecções, ajuda no desenvolvimento mental, o leite materno promove o vínculo afetivo e estabelece uma ligação precoce e muito forte, é importante que ocorra de uma forma prazerosa e em um ambiente tranquilo. Entendemos assim, que o bem estar físico, mental e social proporcionado pelo lei- 
te materno à mãe e ao bebe, mesmo que em condições funestas deve ser incitado no Conjunto Penal.

Diante do contexto, este trabalho traz como questão norteadora: Qual a percepção de mulheres presidiárias sobre o processo de amamentação no Conjunto penal feminino da Bahia, tendo como objetivo: Analisar a percepção de mulheres presidiárias sobre o processo de amamentação no Conjunto penal feminino da Bahia.

\section{METODOLOGIA}

Foi realizada uma pesquisa de campo com abordagem qualitativa. A escolha pela pesquisa qualitativa sucedeu devido ao fato de ser um método de averiguação que enfatiza a percepção do experimento humano como é vivida, através da reunião de dados e identificação dos materiais narrativos, subjetivos em que se permite a percepção da conduta do individuo em determinadas circunstancias. (9) A pesquisa foi realizada em um Conjunto penal Feminino da Bahia.

Foram realizadas entrevistas semi-estruturadas que permitiu um contato mais próximo com essas presidiárias "A entrevista semi-estruturada ao mesmo tempo em que valoriza a presença do investigador, aparece todas as perspectivas possíveis para que o informante alcance a liberdade e a espontaneidade necessária, enriquecendo a investigação".(10)

Os sujeitos foram presidiárias, como critério de seleção: entrevistamos mulheres que se encontravam no ciclo gravídico puerperal e que passaram pelo processo de amamentação no presídio, a coleta foi realizada no mês de Agosto de 2012. Os sujeitos da pesquisa constituíram sete presidiárias, apesar das participantes terem sido oito mulheres, entretanto uma Presidiária preferiu não participar.

O estudo obedeceu às diretrizes e normas de pesquisa com seres humanos contidos na resolução n 196/96 do Conselho Nacional de Saúde. (11) Foi apreciado e aprovado pelo Comitê de Ética em Pesquisa $n^{\circ} 3881 / 12$
As entrevistas foram realizadas conforme roteiro estabelecido onde foi entregue um Termo de Consentimento Informado, sendo as entrevistadas identificadas por codinomes de flores para preservar a identidade das mesmas, estes codinomes foram escolhidos de acordo a percepção do comportamento de cada uma durante a entrevista.

Como técnica de análise de dados foi utilizada a análise temática de Bardin, proposto em quatro fases: pré-análise, exploração do material, tratamento dos resultados e codificação. ${ }^{(12)}$ Resultando em três categorias e suas respectivas subcategorias.

\section{DESCRIÇÃO DOS SUJEITOS DA PESQUISA}

A faixa etária varia de 18 a 33 anos de idade. Desse modo, a maior incidência de mulheres que estão entrando no mundo do crime é jovem. ${ }^{(13)}$ Com relação à situação conjugal no momento da entrevista, quatro presidiárias relataram serem solteiras, duas em união estável e uma viúva.

No que se refere à religião a maioria das presidiárias referiu ser católica. Entretanto observamos que durante as entrevistas não expressaram crença na religiosidade para superar a realidade das situações difíceis da experiência vivida na prisão, de acordo com a naturalidade, observou-se que a grande maioria pertence ao estado da Bahia e apenas uma é do estado do Rio de Janeiro.

Quanto ao número de filhos, quatro reclusas têm um filho, uma tem dois filhos, uma tem três filhos e uma tem cinco filhos. Foi relatado que devido à dependência de drogas uma das presidiárias vendeu o próprio filho para manter o vício, porém a grande maioria demonstrou interesse em permanecer com seus filhos o máximo que puderem.

De acordo com os relatos nenhuma dessas presidiárias engravidaram no presídio. Vivenciamos essa triste realidade, por se tratar de mulheres gestantes envolvidas com a criminalidade perdendo assim o significado da essência feminina. 
Com relação ao grau de escolaridade no gráfico 1 , mostra os seguintes dados, duas presidiárias possui ensino fundamental incompleto; duas ensino fundamental completo; duas ensino médio completo e uma ensino médio incompleto, assim percebemos que mais da metade dessas presidiárias possui baixo nível de escolaridade. Contudo a maior parte das mulheres que transitam na "vida da violação" pertence a uma camada civil menos beneficiada e possui um nível inferior de escolaridade. ${ }^{(13)}$

Gráfico 1 - Grau de escolaridade

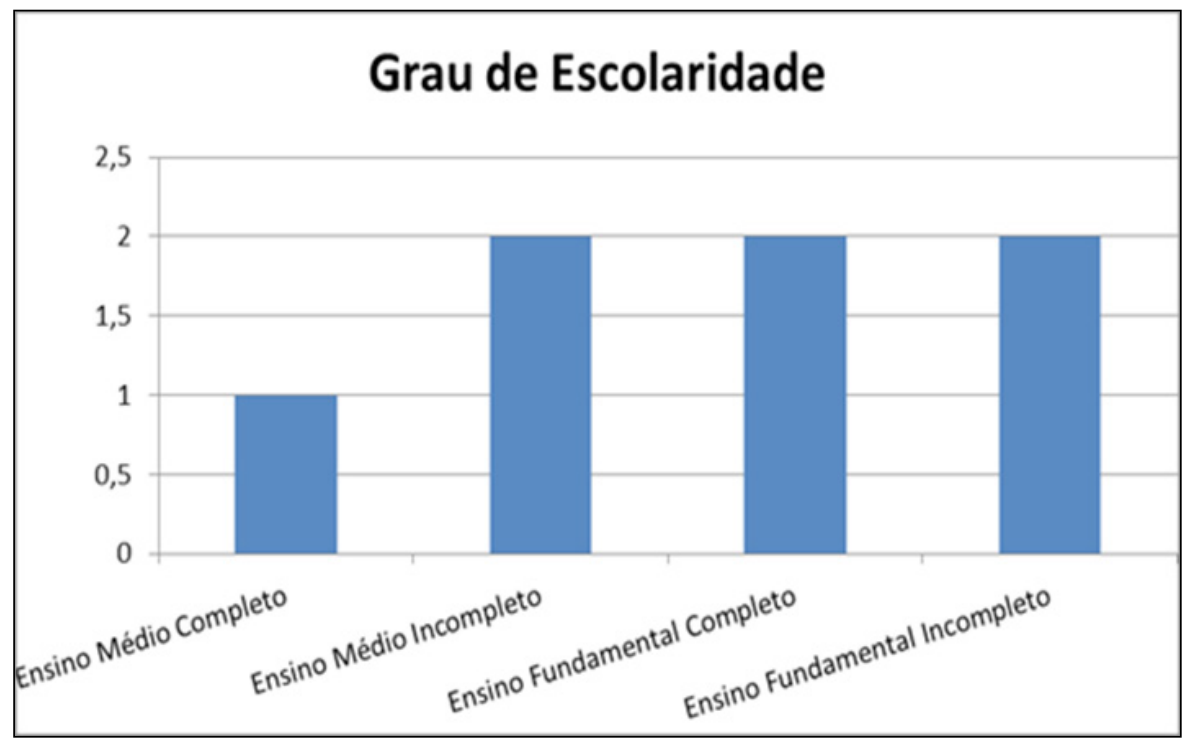

No Gráfico 2, percebemos que a maior taxa dos crimes praticados por essas presidiárias é o tráfico de drogas, tendo em vista que das sete entrevistadas, seis cometeram crime de tráfico e uma de furto "forjado". Sendo elas na sua grande maioria vítimas na condução da droga, atuando como transportadoras, em algumas situações por influencias do meio em que convive ou assumindo o comando de organização criminal em função da prisão do companheiro.

\section{Gráfico 2 - Crimes cometidos}

\section{Crimes Cometidos}

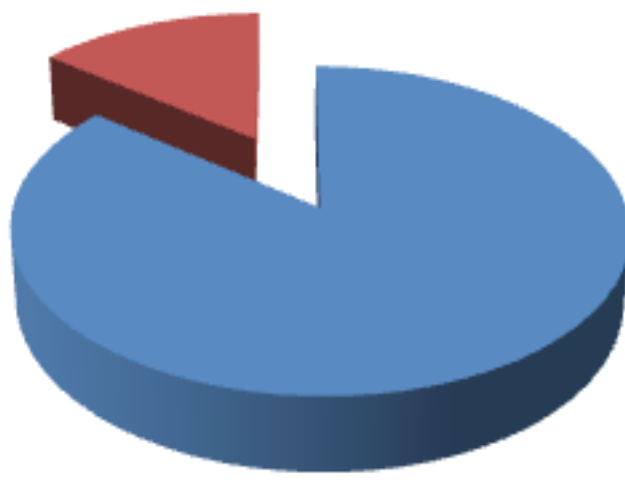

Tráfico

Furto 


\section{RESULTADOS E DISCUSSÃO}

\section{VIVENCIA DA GESTANTE PRESIDIÁRIA}

Essa categoria mostra as dificuldades referidas pelas mulheres que se encontravam no ciclo gravídico puerperal e que passaram pelo processo de amamentação no presídio, a qual se observa diante dos relatos abaixo.

\section{A GRAVIDEZ NO PRESÍDIO E SUAS DIFICULDADES}

Aqui não tem médico na casa, a medica que tinha saiu [...] a gente tá sem ginecologista, que era a única salvação que a gente tinha, ela saiu e só tem a Enfermeira, mais é aquela coisa, você passa e tudo é normal. (Variagada)

[...] alimentação não é tão boa pra gente que precisa comer fruta, não vem, não tem aquela alimentação saudável a gente não tem, tá muito ruim, não vou mentir, tá horrivel!. (Orquídea)

A partir das falas supracitadas, tais ações demonstram uma forma trágica e cruel desse sistema que deveria por designo assegurar os direitos reservados por lei, agravando a essas mulheres que se encontra no ciclo gravídico puerperal, esse tipo de ambiente exerce influência direta no desenvolvimento e estado nutricional do feto assim como a alimentação oferecida é inadequada e insuficiente aos quesitos nutricionais para essa mulher.

A gestação é um momento peculiar na vida de uma mulher. É nesta época que uma boa alimentação é mais importante do que nunca. Uma nutrição balanceada durante a gestação tem maior probabilidade de se ter menos complicações e de terem crianças mais saudáveis.

Sendo assim o cárcere é fator emotivo de constante estresse na vida de qualquer detenta. $O$ estresse da prisão associado à desordem emocional pré-existente no estado gravídico, influenciará no desenvolvimento, pois durante o período de vida intrauterina ele absorve todas as opressões que a mãe passa durante o período gravídico. ${ }^{(13)}$

\section{ESTAR PRESIDIÁRIA E EM COMPANHIA DO BEBE}

Observa-se que o conjunto penal em análise apesar de ter sido construído como unidade prisional feminina este mais equipara àqueles destinados aos homens devido a sua planta física e organização da instituição em não complementar as necessidades ligadas à maternidade, visto que mulheres grávidas e mães que amamentam encontram-se em situações bem peculiares e precárias, por ser um ambiente que não propicia segurança e tranquilidade, fato que pode interferir no sucesso da amamentação e no crescimento do bebê.

Dormia na mesma cama, não tem berço, não tem berçário, [...] mas a criança dorme do lado da gente, e tem cela que fica cinco, sete, oito, dez pessoas. (Violeta)

As outras colaboram, seguram, tem umas que pedem pra lavar roupa. É uma ajudando a outra [...] muitas das mulheres chorou porque minha filha foi embora. (Violeta)

Após o parto, a mulher presa deve ficar em unidade prisional que possua berçário para lactar e cuidar de seu bebê por pelo menos seis meses de vida, na unidade deve haver berçário e equipe de saúde pronta para acompanhar e dar assistência pós-natal a mãe e filho. ${ }^{(4)}$ Em contrapartida observamos que o Conjunto Penal em estudo possui berçário, porém desativado.

Evidenciamos o desrespeito quanto aos direitos desses bebês onde se encontram em celas coletivas superlotadas dividindo a comarca com suas mães, é necessário propiciar um ambiente agradável $\mathrm{e}$ tranquilo, a esse binômio mãe filho no momento 
da amamentação o que não condiz com a realidade vivenciada por essas presidiárias.

Destacamos um fato generoso de solidariedade entre as internas, dedicando assistência a essas crianças no que se refere aos cuidados, higiene com os objetos de uso pessoal, dentre outros, porém, conforme relato das próprias presidiárias observamos os riscos que esses bebês estão suscetíveis como as doenças infectocontagiosas em virtude do ambiente insalubre que estão inseridos.

Nesse contexto a estada dessa criança com sua genitora na prisão ampliam as controvérsias quanto às particularidades do encarceramento feminino Brasileiro. Todavia, compreende que, se a infraestrutura não é adequada para a presa, que dirá para a criança, que contrariando as regras, acabam sofrendo com o encadeamento do encarceramento da mãe, ou seja, a punição se estende a criança. ${ }^{(14)}$

\section{SER GESTANTE E PRESIDIÁRIA: SENTIMENTOS E EXPECTATIVAS}

Questionar sobre a condição de ser gestante e presidiária não foi uma forma de avaliar o serviço prestado pela penitenciária e sim buscar uma forma de avaliar a influência da percepção sobre a assistência recebida, sobre os sentimentos da gestação e amamentação no presídio, bem como suas expectativas e anseios no que se refere ao período de amamentação.

\section{SENTIMENTOS ACERCA DA GESTAÇÃO}

A falta de estrutura para atender as suas necessidades, a convivência com pessoas estranhas e o distanciamento das relações familiares, favorece a essas gestantes presidiárias sentimentos negativos tornando a gestação uma dificuldade de enfrentamento, entretanto mesmo diante destas situações funestas, a perspectiva da maternidade apontou um sentimento bom e de alegria em algumas das mulheres entrevistadas, conforme alegação nas descrições.
Por tá aqui dentro é ruim né. Mas é aquela alegria porque a gente sabe que tem uma criança que vai nascer, [...] o pai dele meu marido tá explodindo lá dentro, não sei como ele vai fazer quando ter essa criança, porque como ele tá preso é mais uma dificuldade". (Variagada)

Ruim né? Agente quer ter carinho da família, porque a gente fica frágil, quer um carinho $e$ não pode ter, [...] então fica ruim por causa disso. (Orquídea)

Estes relatos evidenciaram que, o afastamento da família pode gerar ausência total ou parcial de laços afetivos, em função do papel associador que a família exerce. Comprovam também a literatura que estas mulheres estão mais suscetíveis a perturbações psicológicas quando se refere aos casos de carência afetiva por separações, instabilidade e desestruturação familiar.

Nesta ótica, análises mostram que a presença do companheiro tem importância positiva no desenvolvimento da gestação e minimiza riscos e resultados prejudiciais à saúde do bebê, pois a instabilidade e $\mathrm{o}$ isolamento podem causar riscos físicos e psicológicos. ${ }^{(15)}$

\section{SENTIMENTOS E EXPECTATIVAS DE PRESIDIÁRIAS ACERCA DA AMAMENTAÇÃO}

Essa categoria surgiu a partir da análise das falas quando as gestantes presidiárias apontavam as dificuldades acerca da amamentação. As questões surgiram com timidez, mas denotaram a influência da questão cultural sobre a percepção da amamentação como um ato de amor para as entrevistadas.

Ah! Amamentação para mim é um ato de amor, acho que assim, cê sente mais amor, você vê o bebê amamentando, o gesto de carinho, de afeto, sinto bem em amamentar meu filho. (Margarida) 
[...] é bom uma criança ser amamentada porque têm todas as vitaminas no leite, né [...]. (Orquídea)

As circunstâncias que podem interferir na condição normal de uma amamentação são diversas, entre elas o ambiente no qual estas mulheres estão, não é um ambiente que estimule a amamentação, realidade que pode intervir de maneira negativa no aleitamento.

Entretanto conforme descrições acima as presidiárias manifestaram sentimentos de amor, carinho, e reconhecem a importância do bebê ser amamentado, embora a condição de presidiária traga dificuldades a sua pratica, testemunhou-se que a amamentação é enfrentada por elas como um estado supremo e especial.

Não só os valores nutricionais do leite, mas o ato de amamentar aumentou o afeto entre mãe $\mathrm{e}$ filho, o contato pele a pele, logo após o nascimento e no período de amamentação é benefício para desenvolver o apego e reduzir o número de abandono e rejeição. ${ }^{(16)}$

Vale ressaltar que a enfermagem deve estar envolvida na promoção, incentivo e apoio ao aleitamento materno, conscientizando a essas puérperas que o aleitamento materno é a forma mais eficiente de atender todos os aspectos nutricionais e desenvolver inúmeras vantagens psicológicas e imunológicas que o recém-nascido precisa, sendo exclusivo até o sexto mês de vida e por livre demanda, além de trazer benefícios para a saúde e recuperação pós-parto a essas mães. E assistir quanto à higienização das mamas, forma correta e posicionamento durante a amamentação.

Encontrando esse apoio essas mães se sentem mais confiantes e motivadas a promover o aleitamento aumentando assim seus sentimentos e vínculo entre o binômio mãe-filho.

\section{PERCEPÇÃO DE PRESIDIÁRIAS SOBRE ASSISTÊNCIA PRÉ-NATAL E ORIENTAÇÕES RECEBIDAS}

Descreve-se nessa categoria como as reclusas são assistidas no pré-natal e de que modo recebem orientações dos profissionais da instituição acerca de cuidados com as mamas na gestação e amamentação ou explicações a respeito de suas dúvidas. Estas descrições podem ser fitadas a seguir.

\section{ASSISTÊNCIA PRÉ-NATAL DE GESTANTE PRESIDIÁRIA}

O pré-natal tem como objetivo acolher a mulher desde o início da gravidez até o final da gestação, auxiliando como um momento de aprendizado para a gestante, como também prevenir, identificar ou corrigir possíveis complicações maternas fetais, e explicar a gestante quanto à gestação, parto, puerpério e cuidados com o recém-nascido assegurando no fim da gestação o nascimento de uma criança saudável e o bem estar materno e neonato.

Tem pré-natal tem, ontem eu me senti mal por ela ai me levaram pro Roberto Santos. [...] antes essa do que nenhuma, eu acho que está sendo normal porque já fiz meus exames, minha outra gestação o que eu fiz na rua está sendo feito aqui. (Jasmim)

Oh! [...] qualquer dor que você tem é tudo normal, só lhe passam pra dá buscopan, eu só tive atendimento pré-natal uma vez com a médica, foi razoável, melhoraria porque a gente é gestante, [...]. (Variagada)

O quadro de profissionais de saúde do Conjunto Penal Feminino é composto por médico, enfermeiro, auxiliar de enfermagem, odontólogo, psicólogo e assistente social. Porém o que foi informado e presenciado é que o quadro de profissionais de saúde é insuficiente para atender a 
demanda embora essas presidiárias realizam o pré-natal, mesmo com todas as dificuldades.

Deste modo o Ministério da Justiça e da Saúde estabeleceu o Plano Nacional de Saúde no Sistema penitenciário através da Portaria Interministerial $n^{\circ}$ 1777, de o9 de setembro 2003, que prevê a inclusão da população penitenciaria no sistema único de Saúde (SUS). ${ }^{(17)}$

Durante a gestação, é importante realizar diversos exames. Existem testes obrigatórios, que toda grávida deve fazer, e os específicos, estes são requisitados em situações de perigo, como mulheres com idade superior a 35 anos, história de doenças genéticas ou problemas como hipertensão e diabetes. No acompanhamento pré-natal a necessidade de testes específicos diversifica conforme situação da gestação e avaliação médica. Cuidados como estes durante a gravidez auxiliam a caucionar saúde e bem-estar para a mãe e o bebê. ${ }^{(18)}$

Muitos autores analisam que, mesmo a assistência pré-natal estando presente no alvo das ações exercidas pelos serviços de saúde, até o instante, ficam interrogações que, entre outras, precisam ser questionadas, como a capacidade da assistência ministrada, a ligação entre o pré-natal e o parto, a humanização da atenção e os intoleráveis índices de letalidade materna e perinatal. ${ }^{(19)}$

\section{ACESSO DAS PRESIDIÁRIAS ÀS ORIENTAÇÕES SOBRE GESTAÇÃO/ AMAMENTAÇÃO X O PAPEL DOS PROFISSIONAIS DE SAÚDE.}

As orientações transmitidas pelos profissionais de saúde são imprescindíveis para o resultado de uma boa gestação, pois se trabalha a parte educativa esclarecendo dúvidas, deixando-as mais confiantes e preparadas para a gestação.

Ela explica como agente deve dá o banho, como tratar os seios, tomar banho de sol nos seios, o que o colostro faz e passar nas pontas do seio, explica tudo com relação a isso. (Jasmim)

Não, nenhuma orientação. (Peônia)

Certificou-se que em relação às orientações sobre gestação e amamentação, uma gestante afirmou e uma negou ter conhecimento das orientações dadas pelos profissionais de saúde.

Visto que durante o ciclo gravídico-puerperal o Enfermeiro é o profissional que mais se relaciona com a gestante, promovendo assim o seu papel nos programas de educação em saúde, preparando a gestante durante o processo gravídico relacionado ao preparo das mamas a fim de evitar problemas com os mamilos, conscientizando sobre o aleitamento materno e no processo de adaptação pós-parto, evitando assim dificuldades, dúvidas e possíveis complicações.

É importante o Enfermeiro perceber que a informação dialogada precisa ser fundamentada no exercício do cuidar, e não intentar mudar ou contraprovar a pessoa ou apenas prescrever tratamentos, e sim permanecer preparado para exercer interação, ensinamentos e aprender com o indivíduo e com o coletivo, por meio de ações instrutivas. ${ }^{(20)}$

\section{CONSIDERAÇÕES FINAIS}

Durante a pesquisa foi possível perceber que mesmo com as melhorias que aconteceram ao longo do tempo, como serviços destinados a assistência à saúde para prevenção e cura, acompanhamento médico no pré-natal, pós-parto ao recém-nascido e berçário a fim de caucionar e acatar o acesso das presidiárias aos serviços de assistência concedidos obrigatoriamente pelo Estado no período da execução da pena, no tocante a maneira de lidar e penalizar as pessoas que infringiram as leis determinadas pela sociedade, o que realmente prevalece nas penitenciárias é o cunho de punir, e oprimir, 
esse propósito frente às valiosas conquistas $d a$ legislação penal, dos direitos humanos e sociais, na realidade proporciona prejuízos incomensuráveis à garantia dos direitos e da ressocialização das presidiárias.

Sabe-se que a maioria das instituições penais necessita de acomodações adaptadas e estratégias políticas que propiciem condições dignas as mulheres presas e seus filhos, todavia os estudos mostram que as penitenciárias no Brasil não estão organizadas para acolher gestantes e mães em companhia de seus filhos. No entanto, este estudo revelou que, as condições do presídio da Bahia são ainda piores devido às dificuldades internas em especial dentro das celas como a superlotação, ainda assim, percebemos que o conjunto penal feminino da Bahia corrobora o direito de o bebê ser amamentando enquanto sua mãe cumpre a pena, porém, sofre com a falta de boas práticas para amamentar, por consequência da escassez assistencial e estrutural. Com isso sob a percepção das presidiárias os resultados das entrevistas destacaram que ainda há muito por fazer referente até então à ausência de benefícios no local concedido para amamentação por não serem adequadas para um bebê.

Os resultados aqui apresentados deixaram claro que os funcionários e profissionais de saúde que assistem as mulheres presidiárias no ciclo gravídico puerperal, devem praticar ações com foco na promoção da amamentação, assim, teria um acesso do profissional de saúde à vivência das presidiárias o que motivaria uma atenção mais positiva, tendo em vista que as informações sobre o ato de amamentar têm sido pouco praticadas no conjunto penal, logo, sucede-se em instabilidade para amamentar na prisão e muito provavelmente precisam de estímulo e apoio por estar distanciadas de sua família, encarregando este ofício ao profissional de saúde da unidade prisional.

Embora a problemática sobre o cárcere feminino, a gestação e a existência de uma criança no presídio venha sendo discutida na esfera da segurança pública, ainda se faz necessários estudos científicos para estabelecer políticas de saúde pública mais eficiente sobre aleitamento materno no ambiente prisional, em virtude da realidade particular vivenciada por estas mulheres. Portanto é importante salientar, que embora sejam poucos os presídios que vem implantando e desenvolvendo ações e protocolos no que diz respeito ao atendimento da presidiária no ciclo gravídico puerperal, a sua criação exige uma formação profissional que dê conta das relações de gênero, raça/etnia, e de poder.

Nesse contexto é imprescindível para o atendimento global à mulher presidiária no ciclo gravídico puerperal ou no processo de amamentação o trabalho envolvendo redes e parcerias, o qual deve ser exercido de forma cuidadosa e responsável, uma vez que é necessário romper com a relação assimétrica entre a mulher e o profissional que a assiste.

Outra situação conflitante vivenciada por essas mulheres durante o cumprimento da pena é o preconceito por parte dos profissionais que prestam serviço dentro e fora do presídio, inclusive profissionais de saúde, contudo esse assunto foi pouco mencionado pelas presidiárias. Diante do exposto, é essencial conhecer a fundo a condição dessas mulheres para a realização de um trabalho sério, entender como labutar com elas ao invés de estigmatizá-las.

Defende-se também, que essa temática seja inserida e/ou reforçada nos currículos acadêmicos, através dos cursos de graduação e pós-graduação da área de saúde e áreas afins, contemplando a dimensão da interdisciplinaridade, substituindo os paradigmas da racionalidade, preparando os futuros profissionais de saúde para lidar com a dimensão subjetiva.

Faz-se necessário também o envolvimento dos dirigentes dos serviços que atendem as mulheres presidiárias no ciclo gravídico puerperal, a partir da realização de treinamentos para a sensibilização e capacitação dos profissionais de saúde na detecção do problema, acolhimento, cuidado e/ou encaminhamento para outro serviço, desempenhando, 
assim, um trabalho intersetorial e interdisciplinar, visto que eles se apresentam como um grupo importante na realização de possíveis ações a serem desenvolvidas nesse aspecto. Assim, acredito que tais propostas reduziriam a reprodução de relações desiguais e violentas.

Para a enfermagem, em especial, este estudo se constitui de modo importante no sentido de levá-la a refletir sobre a questão da assistência à mulher presidiária, fazendo-se necessário que os profissionais de enfermagem estejam atentos em respeitar a vivência do outro, além do mais, desenvolvendo estratégias para uma assistência integral associado às políticas sociais.

Entretanto, acredita-se que este trabalho se associe a outros que vem sendo efetivado por profissionais das diversas áreas, contribuindo para que alguns profissionais repensem seus valores, suas atitudes e alguns, identificando-se com esses princípios, desenvolvam, nos serviços, possíveis ações direcionadas para a humanização e, consequentemente, melhoria da assistência prestada.

\section{REFERENCIAS}

1. Oliveira SV. Presidiária do Amapá: percepção sobre a importância de amamentar. Est. Cient. (UNIFAP). 2O11;1(2):127-41.

2. Gomes FL, Bunduky CM. Mulheres presas: aumento de $252 \%$ em dez anos [internet]. Brasília: Gomes LF, Bunduky MC, 2012. [acesso em 2012 fev. 22] disponível em: http://www. institutoavantebrasil.com.br/artigos-do-prof-lfg/ mulheres-presas-aumento-de-252-em-dez-anos/

3. Brasil. Ministério da Justiça. Departamento Penitenciário Nacional. Mulheres Encarceradas - Diagnóstico Nacional. Brasília; 2008.

4. Brasil. Lei n ${ }^{\circ} 11.942$, de 28 de Maio de 2009. Dá nova redação aos arts. 14, 83 e 89 da lei 7.210, de 11 de Julho de 1984. Lei de Execução Penal, para assegurar as mães presas e aos recémnascidos condições mínimas de assistência. Brasília (DF); 28 de Maio de 2009.

5. Brasil. Ministério da Saúde. Saúde da criança: nutrição infantil aleitamento materno e alimentação complementar. Caderno de atenção básica. Brasília (DF); 2009.

6. Silva QR, Gubert BM. Qualidade das informações sobre aleitamento materno e alimentação complementar em sites Brasileiros de profissionais de saúde disponíveis na internet. Ver. Bras. Saúde Matern. Infant. 2010;10(3):331-340.

7. Brasil. Constituição (1988). Constituição da República Federativa do Brasil. Brasília, DF: Senado; 1988.

8. Brasil. Lei n 8.069 , de 13 de Julho de 1990. Dispõe sobre o Estatuto da Criança e do Adolescente e dá outras providencias. Diário oficial da união. 13 de Julho de 1990.

9. Oliveira SL. Tratado de Metodologia Cientifica: projetos de pesquisa, TGI, TCC, monografias, dissertações e teses. São Paulo: Pioneira Thomson Learning; 2002. 32Op.

10. Triviños ANS. Introdução à pesquisa em ciências sociais: a pesquisa qualitativa em educação. São Paulo: Atlas, 1987.

11. Brasil. Conselho Nacional da Saúde - Resolução 196, de 10 de Outubro de 1996. Dispõe sobre diretrizes e normas regulamentadoras de pesquisas envolvendo seres humanos. Bioética. 1996.

12. Bardin L. Análise de Conteúdo. Lisboa: 70 ed. 1979.

13. Viafore D. A gravidez no cárcere Brasileiro: uma análise da penitenciária feminina Madre Pelletier. Direit. \& Just. XXVII; 31(2):91-108.

14. Lima GG. Sistema Prisional Paulista e Organizações Criminosas: a problemática do PCC - primeiro comando da Capital [dissertação de mestrado]. São Paulo: Universidade Metodista de Piracicaba UNIMEP; 2009.

15. Costa MCO, Lima IC, Júnior MFD, Santos CAST, Araújo FPO, Assis DR. Gravidez na adolescência e co-rresponsabilidade paterna: trajetória sociodemográfica e atitudes com a gestação e a criança. Ciência \& Saúde Coletiva. 2005;10(3):719-727.

16. Rego JD. Aleitamento materno, $2^{\mathrm{a}}$ ed. São Paulo: Atheneu, 2006. 
17. Brasil. Ministério da Justiça e da Saúde. Portaria Interministerial $n^{\circ} 1.777$, de 09 de Setembro de 2003.

18. Brasil. Ministério da Saúde. Cuidados durante a gravidez. Portal Brasil; 2O1O. [acesso em 2012 set. 21] disponível em: http://www.brasil.gov.br/ sobre/saude/maternidade/gestacao/
19. Gonçalves R, Urasaki MBM, Merighi MAB, D’Avila CG. Avaliação da efetividade da assistência pré-natal de uma Unidade de Saúde da Família em um município da Grande São Paulo. Rev Bras Enferm. 2008;61(3):349-53.

20. Figueiredo NMA, Tonini T. SUS e PSF para enfermagem: práticas para o cuidado em saúde coletiva. $1^{\mathrm{a}}$ ed. São Paulo: Yendis, 2008. 272p. 